\title{
Adequação ambiental dos processos usinagem utilizando Produção mais Limpa como estratégia de gestão ambiental
}

\author{
João Fernando Gomes de Oliveira \\ NUMA-USP \\ Salete Martins Alves \\ SOCIESC
}

\begin{abstract}
Resumo
A necessidade da indústria de se adequar ambientalmente tem feito com que muitas empresas revejam seus processos. Considerando as legislações vigentes e a demanda por produtos e processos considerados "verdes", tem motivado a busca por metodologias de gestão ambiental. Este artigo tem o objetivo de apresentar a Produção mais Limpa $(\mathrm{P}+\mathrm{L})$ como uma metodologia que auxilia as indústrias a obter uma boa gestão ambiental, mostrando um estudo de caso do processo de usinagem. Os resultados desta pesquisa demonstram que o processo de usinagem pode ser adequado ao meio ambiente através da redução dos fluidos de corte ou de uma boa manutenção dos mesmos.
\end{abstract}

Palavras-chave

$\mathrm{P}+\mathrm{L}$, usinagem, fluidos de corte, meio ambiente, minimização de resíduos.

\section{Environmental adequacy of machining processes using Cleaner Production as strategy of environmental management}

\begin{abstract} of cutting fluids or a good maintenance of their characteristics..

Key words

Cleaner production, machining, cutting fluids, environment, waste minimization.
\end{abstract}

The need for the environmental adequacy of industry has induced many companies to review their manufacturing processes. Considering the effective legislations and the demand for "green" considered products and processes, it has motivated the search for methodologies of environmental management. The objective of this paper is to present Cleaner Production as one methodology that it aims the industries to obtain a good environmental management, showing as case study that the machining process can be adapt to environment through the reduction in the usage 


\section{INTRODUĈ̣̃O} tria de manufatura tem sido observado devido a aumento da poluição, desenvolvimento de legislações preventivas e crescimento da demanda de produtos e processos de produção "verde". Até recentemente, os esforços industriais para aliviar os impactos ambientais de seus produtos e processos estavam focados em duas áreas: desenvolvimento de um processo de reciclagem, especialmente para metais e plásticos, e substituições de produtos químicos nos processos de manufatura, tornando-os processos denominados "processos limpos".

Um dos processos mais utilizados na manufatura em geral é a usinagem. O uso de fluidos de corte neste processo é comum, devido à melhora nas condições tribológicas. $\mathrm{O}$ emprego de fluido de corte aumenta a vida da ferramenta, minimiza a geração de calor durante o processo, auxilia na remoção dos cavacos e geralmente melhora a eficiência do sistema produtivo.
Um maior interesse pela consciência ambiental da indús-

do processo. Estes são caracterizados com relação ao tipo, quantidade e estado físico.

Este artigo tem como objetivo avaliar os impactos ambientais decorrentes do uso dos fluidos de corte nos processos de usinagem e, com o auxílio da ferramenta de gestão ambiental chamada "Produção mais Limpa", definir uma proposta de redução dos resíduos gerados neste processo, através de mudanças no produto e processo.

\section{IMPACTOS AMBIENTAIS EXTERNOS E INTERNOS CAUSADOS PELOS FLUIDOS DE CORTE}

A utilização de fluidos de corte no processo de usinagem faz da indústria metal-mecânica uma potencial agressora do meio ambiente. São vários os problemas decorrentes desta utilização, que vão desde a geração de efeitos nocivos ao ambiente de trabalho até a agressão do meio ambiente.

Ao avaliar os impactos gerados pela utilização dos fluidos de corte, devemos considerar dois principais efeitos: efeitos nocivos à atmosfera (interna e externa) e degradação do solo e recursos hídricos, como está demonstrado na Figura 1.

Os fluidos de corte podem ser disAtilização de fluidos de corte no processo
mecânica umagem faz da indústria metal-
mearessora do meio ambiente. postos depois de seu uso pela própria companhia ou por uma empresa especializada em disposição de resíduos. Dependendo da qualidade e modo de disposição do resíduo, o resultado será poluição do solo, águas e ar. Deve ser

Em contrapartida, devido à multiplicidade de efeitos negativos gerados pela utilização dos fluidos de corte, tais como danos ao meio ambiente e agressão à saúde do operador, especial atenção está sendo voltada à seleção eficiente de tais fluidos de corte, por garantir menores impactos ao meio ambiente. As restrições resultantes da legislação não conduzem apenas às limitações e dificuldades com processos de manufatura e a um acréscimo de custo indesejável a elas associado, mas também força a desenvolver tecnologias novas e alternativas. Isto representa um novo desafio tecnológico aos cientistas e engenheiros e aumenta a importância da manufatura ecológica como um fator competitivo.

A consideração de questões ambientais na manufatura exige a realização de uma análise do processo total, no qual todos os insumos de entrada e saída sejam analisados e os efeitos exatos de energia e ambiente de cada parâmetro sejam avaliados de maneira quantitativa. Sokovic\&Mijanovic (2001) exemplificaram este procedimento para o processo de usinagem. Ferramenta, peça de trabalho, materiais processados e energia são as variáveis de entrada. Do outro lado, após o processamento, tem-se um produto que demonstra as características requeridas em termos de qualidade, eficiência econômica e reciclabilidade. Ainda, têm-se os materiais residuais e as emissões, os quais são partes indesejadas considerado que os fluidos de corte mudam sua composição durante a usinagem, ocasionando também uma mudança nos riscos oferecidos ao meio ambiente. Podem ser formadas ainda substâncias secundárias, produtos de reações originados durante o processo, corpos estranhos e microorganismos que são agregados ao fluido de corte.

Não são apenas os problemas de disposição que despertam interesse, mas as perdas de fluidos de corte podem também ser muito prejudiciais e custosas. Elas ocorrem no sistema de manufatura pela vaporização na usinagem, na saída de cavacos e peças da máquina, nos componentes da máquina, tais como dispositivos de fixação e manuseio, no vácuo, nos sistemas de pressurização do ar e na formação de gotas e vazamentos. O vazamento do fluido é um fator crítico que contribui para a perda e, em alguns casos, para as influências negativas nos sistemas hidráulicos da máquina.

Na utilização de fluidos de corte, peças molhadas e sujas, assim como cavacos e partículas, saem do sistema da máquina e entram no sistema de limpeza e secagem. Segundo Byrne (1996), cerca de 30\% do consumo total anual de fluido de corte é perdido através da remoção do sistema pelos meios mencionados acima, o que torna evidente a necessidade de se encontrar métodos eficazes para combater tais perdas. 
O manuseio incorreto dos fluidos de corte pode gerar resultados desagradáveis que vão desde problemas no processo de fabricação e ataques à saúde dos operadores até o descarte prematuro deste produto. Para garantir um menor impacto dos fluidos de corte à saúde dos operadores e à qualidade do meio ambiente, gerentes e operadores devem estar cientes de todos os cuidados que são indispensáveis na sua aplicação, usando das medidas de precaução fornecidas pelo fabricante e órgãos ambientais, evitando assim a ocorrência de resultados desagradáveis.

A aplicação dos fluidos de corte nos processos de usinagem gera vapores, sobretudo, no contato do refrigerante com superfícies quentes e em movimento da peça trabalhada, da ferramenta, ou do cavaco, comprometendo o ar do local de trabalho. A pressão e o aquecimento do fluido de corte também exercem influência no grau de evaporação. Este comprometimento do ar, em decorrência do uso de aerossóis e dos vapores de agentes refrigerantes, varia em função, por exemplo, das propriedades físico-químicas do fluido de corte, da velocidade de rotação das peças que estão sendo trabalhadas e do aquecimento das superfícies.

Acredita-se que há substanciais evidências de aumento do risco de câncer, em diferentes órgãos do corpo humano, associado com a utilização dos fluidos de corte. O tipo e quantidade dos constituintes químicos dos fluidos podem variar para as diferentes classes, alguns destes componentes são considerados carcinogênicos, como por exemplo a $\mathrm{N}$-nitroamina. Dentre os diversos tipos de fluidos de corte o que tem se revelado mais agressivo à saúde do operador é o óleo integral. O solúvel é o menos agressivo. Porém, através dos poucos estudos realizados sobre os efeitos dos fluidos à saúde do operador, é prematuro concluir que todos os membros da classe dos óleos solúveis estão livres de ter algum risco carcinogênico, pois deve-se considerar que o óleo solúvel contém muitos ingredientes encontrados nos óleos integrais, mas em diferentes concentrações.

\section{PROPOSTA PARA APLICAC̣ÃO DA METODOLOGIA P+L (PRODUC̣ÃO MAIS LIMPA)}

O conceito de Produção mais Limpa foi criado pela UNEP (United Nations Environmental Program) em 1988. Segundo a UNEP, a Produção mais Limpa é a aplicação contínua de uma estratégia ambiental preventiva e integrada,

Figura 1: Emissões de resíduos de fluidos de corte.

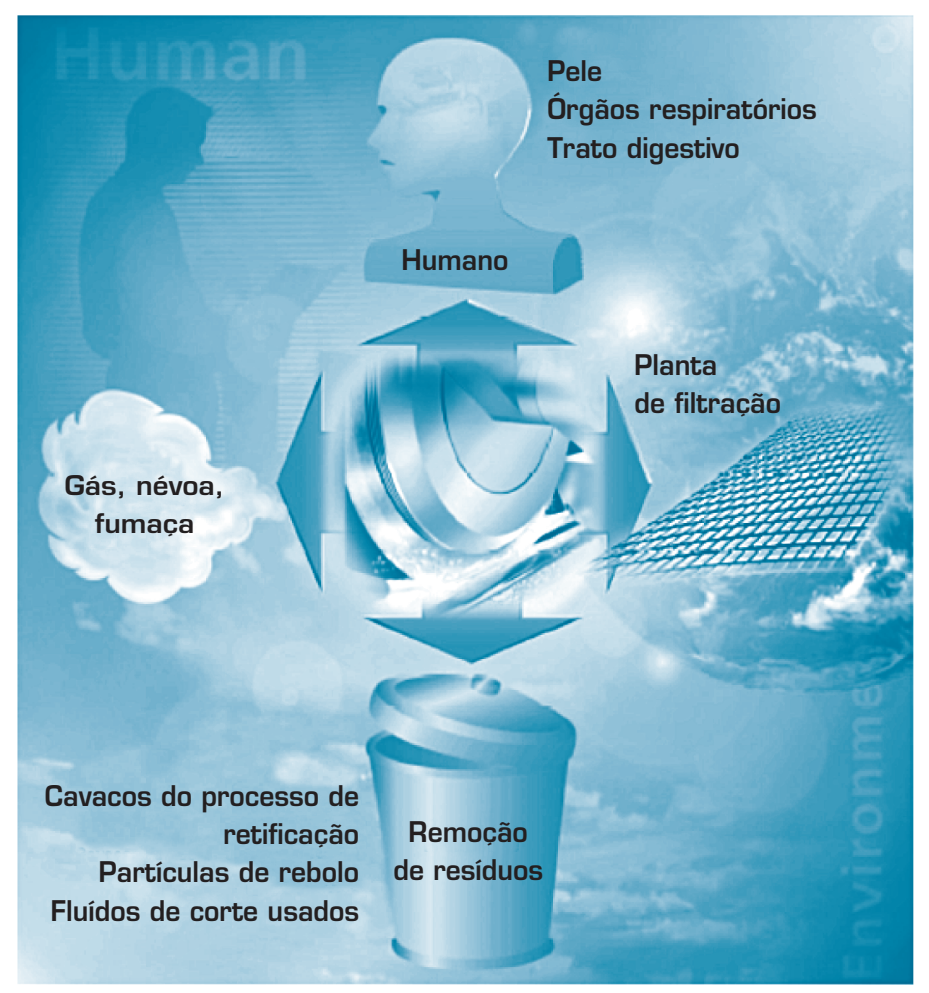

Fonte: ALVES,2006. 
aplicada a processos, produtos e serviços. Incorpora o uso mais eficiente dos recursos naturais e, conseqüentemente, minimiza a geração de resíduos e poluição, bem como os riscos à saúde humana. Para os processos a $\mathrm{P}+\mathrm{L}$ inclui a conversão de matérias-primas e energia, eliminado o uso de materiais tóxicos e reduzindo a quantidade de toxicidade de todas as possíveis emissões e resíduos. Para produtos, a $\mathrm{P}+\mathrm{L}$ inclui a redução dos efeitos negativos do produto ao longo de seu ciclo de vida, desde a extração das matérias-primas até a disposição final do produto. é necessário que se trabalhem as três fases do ciclo de vida do produto: a manufatura, o seu uso e o seu descarte final. Assim, é melhor eliminar o poluente do que tentar recuperá-lo.

Para a produção mais limpa, talvez o mais importante sejam as habilidades básicas e o conhecimento tácito das empresas. São aspectos invisíveis baseados no learningby-doing vistos como difíceis de reproduzir, pautados na experiência acumulada das pessoas e seu refinamento com a prática, enfatizados na teoria dos recursos internos (MELLO, 2002).

A Tabela 1 mostra alguns dos possíveis resultados (tangíveis e intangíveis) que as empresas que implementam a $\mathrm{P}+\mathrm{L}$ podem obter.

Diante desta necessidade, o pre-

As técnicas de produção mais limpa consistem em eliminar todo e qualquer desperdício, pois o desperdício é tudo aquilo que não agrega valor ao produto ou serviço.

Segundo Romm (1996), a reciclagem dos resíduos gerados por processos industriais é louvável, porém se torna bem mais econômico e correto evitar ou minimizar a sua geração. A prevenção à poluição, ou a sua eliminação acaba induzindo os trabalhadores e gerentes a pensarem em melhorias sistemáticas dos processos, passando a não se preocupar em administrar e operacionalizar os resíduos ou a poluição gerada.

Segundo Andrés (2001), para que se atinjam os objetivos de minimização do consumo de recursos e da poluição sente trabalho propõe a abordagem da adequação ambiental associada ao fluido de corte que se inspira na metodologia de produção mais limpa. Nessa metodologia é feito o controle dos fluxos de matéria e energia de modo que o uso eficiente destes recursos naturais seja fator de redução dos efeitos nocivos ao ambiente.

Tecnologias ambientais convencionais trabalham principalmente no tratamento de resíduos e emissões gerados em um processo produtivo. São as chamadas técnicas de fim-de-tubo. A Produção mais Limpa pretende integrar os objetivos ambientais aos processos de produção, a fim de reduzir os resíduos e as emissões em termos de quantidade e periculosidade.

Tabela 1: Possiveis resultados tangiveis e intangiveis da implementação da $P+L$.

\begin{tabular}{|c|c|}
\hline RESULTADOS TANǴEIVEIS & RESULTADOS INTANGIVEIS \\
\hline $\begin{array}{l}\text { 1. Geração de inovações tecnológicas de processo, } \\
\text { produto e gerencial } \\
\text { 2. Benefícios advindos de vantagens comerciais } \\
\text { [concessão de financiamentos, obtenção de } \\
\text { seguros com taxas mais ativas, facilidade para } \\
\text { tornar-se fornecedor de grandes empresas] } \\
\text { 3. Melhoria da competitividade (através da redução de } \\
\text { custos ou melhoria da eficiência) } \\
\text { 4. Redução de custos com matérias-primas, insumos } \\
\text { e energia } \\
\text { 5. Ocorrência de melhorias econômicas de curto prazo } \\
\text { 6. Novas oportunidades de negócios } \\
\text { 7. Minimização dos riscos no campo das obrigacões } \\
\text { ambientais } \\
\text { 8. Redução dos encargos ambientais causados pela } \\
\text { atividade industrial }\end{array}$ & $\begin{array}{l}\text { 1. Desenvolvimento econômico mais sustentado } \\
\text { 2. Melhoria da qualidade ambiental do produto } \\
\text { 3. Melhoria da imagem pública da empresa } \\
\text { 4. Aumento da eficiência ecológica } \\
\text { 5. Melhoria das condições de trabalho dos } \\
\text { empregados } \\
\text { 6. Aumento da motivaçnao dos empregados } \\
\text { 7. Diversidade de benefícios para as empresas bem } \\
\text { como para toda a sociedade } \\
\text { 8. Indução do processo de inovação dentro das } \\
\text { empresas } \\
\text { 9. Aumento da segurança dos consumidores dos } \\
\text { produtos }\end{array}$ \\
\hline
\end{tabular}

Fontes: LEMOS, 1998. 
A Figura 2 mostra as várias estratégias utilizadas visando a Produção mais Limpa e a minimização de resíduos.

A prioridade da Produção mais Limpa está no topo (à esquerda) do fluxograma: evitar a geração de resíduos e emissões (nível 1). Os resíduos que não podem ser evitados devem, preferencialmente, ser reintegrados ao processo de produção da empresa (nível 2). Na sua impossibilidade, medidas de reciclagem fora da empresa podem ser utilizadas (nível 3).

A prática do uso da Produção mais Limpa leva ao desenvolvimento e implantação de Tecnologias Limpas nos processos produtivos.

Para introduzirmos técnicas de Produção mais Limpa em um processo produtivo, podem ser utilizadas várias estratégias, tendo em vista metas ambientais, econômicas e tecnológicas. A seguir serão detalhadas algumas destas estratégias aplicadas aos fluidos de usinagem.

\section{Elaboração de um balanço ambiental, econômico e tecnológico do processo produtivo.}

Considerando uma empresa do setor metal-mecânico que represente a maioria das empresas que utilizam fluidos de corte, Figura 3, observa-se o alto consumo de matériasprimas e recursos naturais. Após o processamento, tem-se, além do produto, emissões atmosféricas, resíduos sólidos misturados com fluidos de corte e efluentes líquidos.

O balanço ambiental documenta o material e a energia que entram e saem do processo, avaliando quais os impactos provenientes desta atividade ao ambiente, tanto no uso de recursos naturais, muitas vezes feito de forma irracional, como na geração e emissão de resíduos sólidos, líquidos ou gasosos.

Um pré-requisito para a identificação de resíduos e emissões indesejáveis é conhecer o processo tão amplamente quanto possível. Em muitos casos faltam dados importantes com relação à condição e ao comportamento do processo.

O balanço do processo documenta entrada e saída de energia e materiais. Fazendo o balanço no processo de usinagem, pode-se exercer um controle sobre os materiais e sobre a energia. A partir destas informações, pode-se estabelecer um controle de parâmetros de cada operação o que possibilita a escolha da estratégia mais adequada à empresa para a redução de resíduos e de seus efeitos.

Figura 2: Escopo de atuação da metodologia Produção mais Limpa $(P+L)$.

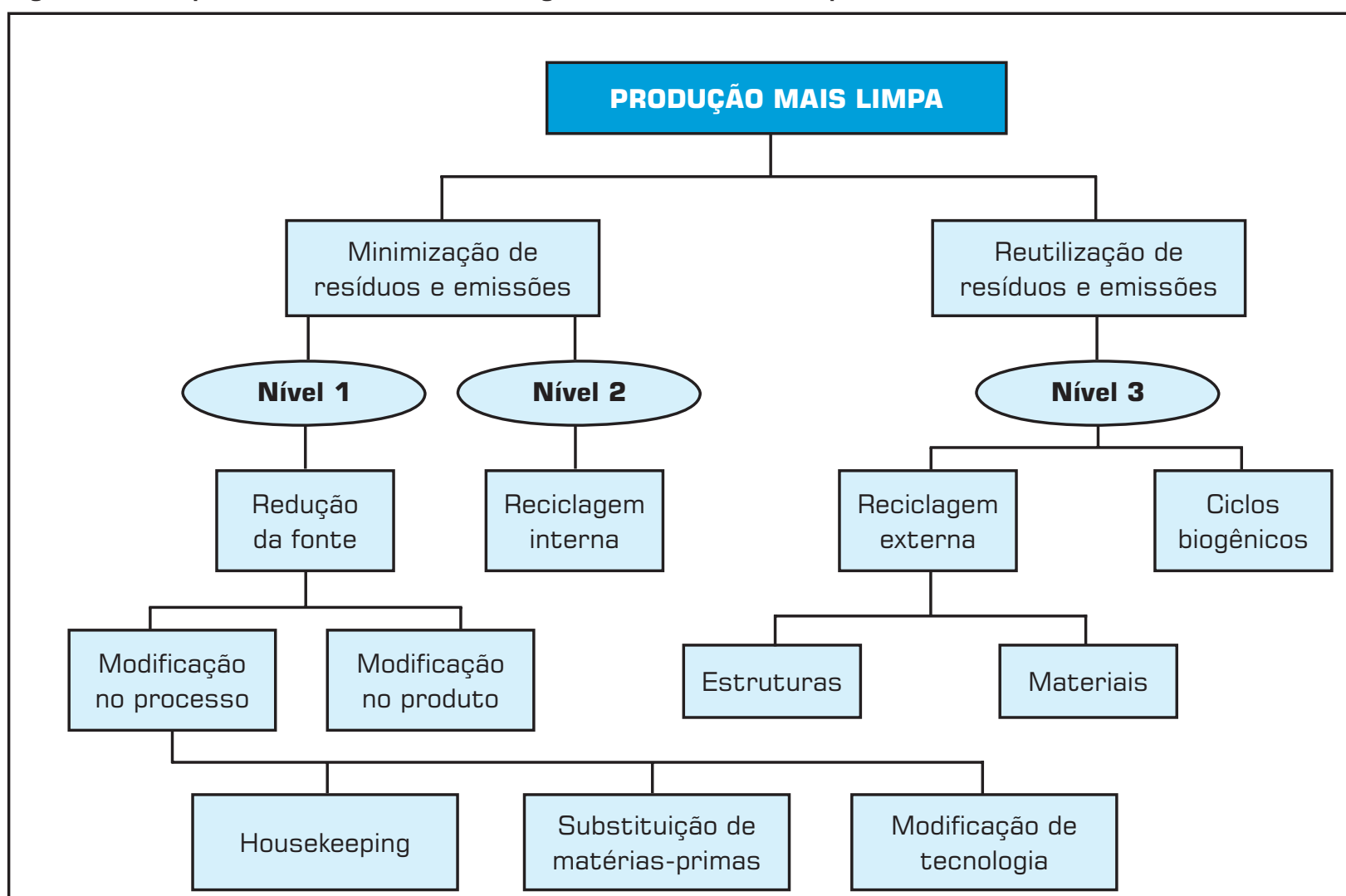

Fonte: CNTL - Centro Nacional de Tecnologias Limpas. 
Depois de realizado o balanço de material é necessário fazer uma análise crítica das informações obtidas, enfocando:

- Quantidades e toxicidade dos resíduos gerados e das matérias-primas consumidas;

- Regulamentos legais que deviam ser cumpridos para utilização e disposição dos materiais e resíduos; e

- Custos envolvidos: os de compra, os de tratamento e os relativos a possíveis punições do órgão ambiental.

\section{APLICAC̣ÃO DO P+L PARA O PROCESSO DE USINAGEM}

Após avaliar as causas da geração de cada resíduo identificado passa-se a refletir sobre possíveis oportunidades de mudança, ou seja, opções $\mathrm{P}+\mathrm{L}$ para deixar de gerar os resíduos. Serão abordadas possibilidades de redução de resíduos na fonte e reciclagem interna dos resíduos.

\section{Redução na Fonte}

Seguindo o diagrama da Figura 2, primeiro analisa-se a possibilidade de redução na fonte, avaliando a viabilidade de modificação no processo e no produto:

a. Modificação no produto - um exemplo de alteração no produto é a otimização no projeto da peça, se trabalhar com peça com dimensões mais próximas à da peça acabada ter-se-á no final do processo uma menor quantidade de cavacos.

b. Modificação no processo - nesta etapa existem três possibilidades: Housekeeping, substituição de matérias-primas e modificação da tecnologia.

\section{Housekeeping}

Os efeitos adversos que decorrem da utilização de fluidos de corte são vários, entretanto, associados a cada um deles estão os procedimentos de manuseio. São procedimentos, na maioria das vezes, muito simples, mas que têm grande valor preventivo, podendo evitar a grande maioria dos problemas ambientais enfrentados no cotidiano. Alguns dos principais procedimentos são apresentados a seguir:

a) Procedimentos preventivos na seleção dos fluidos de corte:

Entre os procedimentos preventivos mais importantes estão o estabelecimento de uma gestão integrada entre a empresa e o fornecedor de fluido de corte na busca pelo melhoramento contínuo de seu gerenciamento. Neste sentido, a empresa, ao selecionar os seus fornecedores, deve seguir alguns princípios:

Figura 3: Geração e emissão de resíduos em uma indústria metal-mecânica típica.

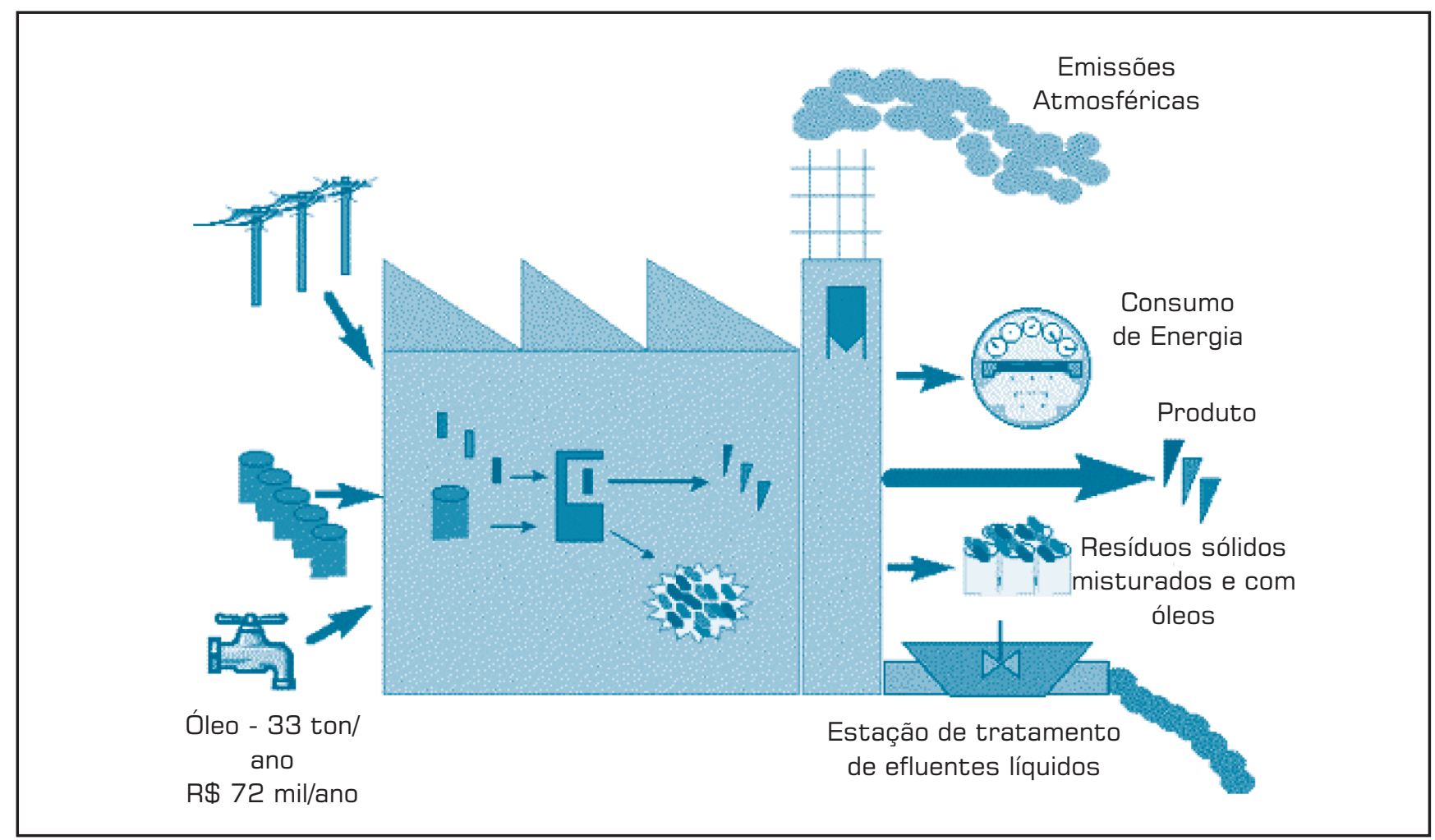

Fonte: CNTL- Centro Nacional de Tecnologias Limpas. 
- Evitar fornecedores que não ofereçam garantias de procedência, assistência e composição dos fluidos de corte;

- Evitar fornecedores que não ofereçam suporte de informações ao programa de manejo ambiental da empresa.

b) Procedimentos durante a utilização:

- Desenvolver procedimentos que promovam hábitos de higiene no trabalho;

- Treinar corretamente os operadores para evitar qualquer hábito que provoque contaminação;

- Estabelecer procedimentos aos equipamentos para que o conjunto esteja adequado aos requisitos da operação;

- Observar a direção e a concentração do jato do fluido para que sua função seja mais eficiente.

c) Procedimento durante a recuperação:

- Avaliar a eficiência dos processos de reciclagem dos fluidos;

- Planejar operações que controlem a concentração dos fluidos, mantendo-as dentro das porcentagens recomendadas pelo fabricante;

- Monitorar a concentração de biocidas e o pH do fluido em operação;

- Seguir as recomendações do fabricante;

- Observar a qualidade e a quantidade de água utilizada para a diluição do concentrado;

- Misturar sempre a água sobre o concentrado, evitando, assim, a mistura invertida;

- Agitar corretamente a mistura no momento da diluição do concentrado;

d) Procedimentos durante o trata-

mento e disposição final:

- Registrar a quantidade de fluidos que entra e sai do processo;

- Registrar as substâncias nocivas do fluido e seus resíduos.

\section{Substituição de matérias-primas}

Podem-se substituir fluidos de óleo mineral por fluidos que sejam feitos com óleo vegetal. Possuem algumas vantagens como: maior facilidade de degradação, ou seja, pode-se aplicar tratamento biológico e químico nos resíduos. Possuem maior lubricidade do que os outros fluidos solúveis, melhorando a qualidade final da peça. Não agridem a saúde do operador. Estes fluidos são geralmente chamados de "amigos do ambiente". Os seguintes pontos devem ser observados na consideração da questão de fluidos de corte para uma produção mais limpa:

- Os constituintes do fluido de corte não podem ter efeitos negativos sobre a saúde do funcionário de produção ou sobre o meio ambiente e devem ser isentos de cloro/ parafina, formaldeído, nitretos, metais pesados e outras substâncias nocivas;

- Durante o seu uso, os fluidos de corte não podem produzir contaminantes.

Alves (2005) desenvolveu um fluido de corte à base de óleo de mamona, o qual não tinha em sua formulação nenhum constituinte agressor ao meio ambiente e à saúde do operador. Além de ser biodegradável este produto ofereceu bons resultados quando utilizado no processo de retificação, semelhantes aos obtidos quando se utiliza óleo mineral.

Além de substituir os fluidos de corte tradicionais, podemse utilizar ferramentas com materiais que permitam usinar a seco. Materiais para ferramentas adequados a altas temperaturas e, portanto, a altas velocidades de corte, permitem a usinagem com forças de corte menores. Uma ferramenta como o CBN permite reduzir o atrito na interface ferramenta/peça, como também a aplicação de geometrias complexas de ferramentas, gerando forças de usinagem reduzidas e superfícies de peças de alta qualidade, com baixa rugosidade. Caso se utilizem ferramentas com recobrimento de TiN e TiAlN no torneamento a seco tem-se um aumento da vida da ferramenta em $300 \%$, muito superior aos valores obtidos no torneamento com fluido de corte (DÖRR, 1999).

\section{s procedimentos de manuseio de fluido de problemas ambientais enfrentados no cotidiano}

\section{Modificação da tecnologia}

A tecnologia mais utilizada para refrigeração durante a usinagem é de inundação, ou seja, uma grande quantidade de fluido de corte é lançada continuamente na região de corte, exigindo o consumo de um grande volume de fluido de corte. Atualmente existem tecnologias que minimizam ou mesmo eliminam o uso destes fluidos, como por exemplo:

- Mínima Quantidade de Lubrificante (MQL): Uma técnica muito estudada nos dias atuais é o corte com mínima quantidade de lubrificante (MQL), onde uma quantidade mínima de óleo (geralmente $<80 \mathrm{ml} / \mathrm{h}$ ) é pulverizada em um fluxo de ar comprimido. Em alguns casos, esta quantidade pode ser ultrapassada, dependendo do volume de cavaco e do processo de usinagem. Esta mínima quantidade de óleo é suficiente para reduzir o atrito da ferramenta e ainda evitar aderências de materiais (DÖRR; SAHM, 2000). Porém, está técnica possui vantagens e desvantagens em relação à usinagem com fluido abundante, as vantagens são: redução do volume de descarte, 
produção de peças e cavacos mais limpos, redução de custos de processamento, limpeza e acondicionamento. Contudo, possuem desvantagens. Duas delas são a névoa e a fumaça de óleo geradas durante o uso da mínima quantidade de lubrificante na usinagem que podem ser considerados subprodutos indesejáveis, pois contribuem para aumentar o índice de poluentes em suspensão do ar e tornam-se fatores de preocupação. Assim, embora o uso de quantidade mínima de fluido não exija preocupação com o descarte e reciclagem do óleo e do cavaco é necessário que se tenha um bom sistema de exaustão na máquina. Também com a utilização da MQL pode-se ter, em alguns processos, um maior desgaste da ferramenta. (MACHADO et al., 2000).

Uma comparação de custos das usinagens por inundação e a MQL foi feita com relação a custos dos investimentos, dos custos fixos e proporcionais anuais na BMW da Alemanha. A confrontação dos custos totais de investimento na linha transfer, inclusive do equipamento para limpeza de cavacos, comprovou vantagens financeiras de $22 \%$ na usinagem com a tecnologia MQL (DÖRR, 1999).

- Usinagem a seco: eliminação total dos fluidos de corte no processo. Só viável quando o tempo de usinagem, o tem- po de vida da ferramenta e a qualidade superficial da peça for pelo menos semelhante à conseguida com a usinagem usando-se fluidos de corte tradicionais. As vantagens desta tecnologia são o atendimento aos requisitos ecológi$\cos$, redução de custos (eliminação do fluido) e aumento da produtividade (devido ao incremento nos parâmetros de usinagem). Porém, existem algumas desvantagens, tais como problemas provocados pelas poeiras produzidas pela operação a seco (associadas à usinagem de ferros fundidos), maior solicitação térmica da peça, provocando um efeito negativo na qualidade final da peça e necessidade de ferramentas especiais. A usinagem a seco necessita de novas soluções no sistema ferramenta-máquina-peça-processo. No caso de ferramentas, os revestimentos desempenham um papel importante, juntamente com outros materiais e geometrias. Por outro lado, como a distribuição de calor é afetada, deve-se pensar em uma concepção mais adequada para a máquina-ferramenta. A máquina para trabalhar com usinagem a seco deve ter um sistema eficiente de transporte dos cavacos. Também deve-se considerar os parâmetros de usinagem, os quais devem ser escolhidos de maneira a obter tempos de corte não muito mais elevados comparativamente à usinagem com fluidos.

Filho et al. (2001), com base nos resultados de experi-

Figura 4: Equipamentos de gerenciamento de fluidos utilizados nas operações de transformações de metais.

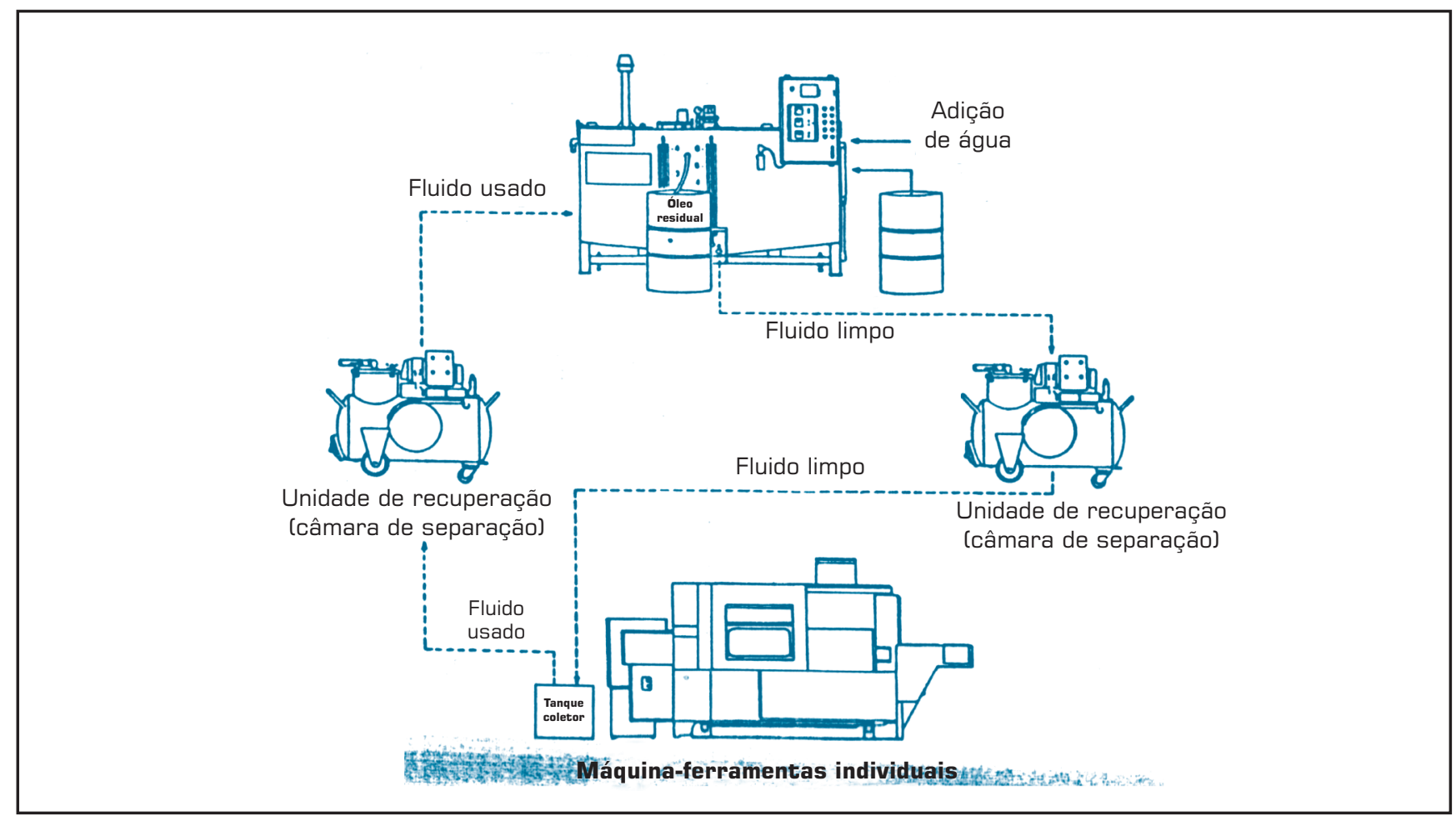

Fonte: DICK E FOLTZ, 1997. 
mentos realizados pelos os autores, concluíram que a condição de corte a seco apresentou o melhor desempenho no torneamento do aço ABNT endurecido. Este fato está relacionado com a maior vida da ferramenta de PCBN do que na condição de refrigeração abundante.

\section{Reciclagem Interna}

Esgotadas as alternativas de reduzir os resíduos na fonte, analisam-se as possibilidades de reciclagem interna. Para a usinagem o mais indicado seria a recuperação e reciclagem do fluido de corte utilizado, podendo o mesmo retornar ao processo. Na Figura 4 é mostrado um sistema de reciclagem por tratamento intermitente, capaz de remover os contaminantes (óleo, sujeira, bactéria) e reajustar com a freqüência necessária a concentração do fluido antes do seu retorno à máquina individual.

Por último, é verificada a possibilidade de agregar valores aos resíduos gerados, neste caso poderia comercializar os cavacos limpos com outras empresas ou sucateiros. Os fluidos de corte poderiam ser comercializados para uma empresa que faça o re-refino do mesmo.

\section{IMPLANTAC̣̃̃O DAS OPORTUNIDADES DE PRODUÇÃO MAIS LIMPA LEVANTADAS E PRIORIZADAS.}

Depois de analisada a viabilidade das oportunidades levantadas, é necessário que a equipe responsável pelo processo de implementação de $\mathrm{P}+\mathrm{L}$ na empresa, liste as oportunidades por ordem de prioridades. Depois de de- terminadas quais são prioritárias, é feita a implantação. A Tabela 2 mostra as barreiras e os benefícios de cada alternativa proposta.

A Tabela 2, ordena as opções por ordem de prioridade, sendo a primeira o housekeeping, pois pode ser implantada em curto prazo e tem baixo custo, também não altera o processo e traz benefícios econômicos e ambientais. A segunda opção o MQL gera um grande ganho ambiental, mas necessita de mudanças na máquina envolvendo um custo de implantação. As alternativas são de longo prazo devido ao grande investimento em máquinas e desenvolvimento de produto.

\section{CONCLUSÕES}

A consciência ambiental, que cresce consideravelmente a cada ano, aumento dos problemas de descarte e a legislação mais severa obrigam que mais indústrias se aprofundem nas questões de compatibilidade ambiental das suas produções.

Com as crescentes cobranças civis e legislativas acerca da relação indústria e meio ambiente, não se permite às empresas continuarem com as velhas tecnologias de fim-de-tubo, ou seja, apenas tratar ou reciclar os resíduos e as emissões gerados, deve-se tentar reduzi-los ou eliminá-los. Uma tecnologia que alcance este resultado é a implementação do conceito de produção mais limpa.

A aplicação da metodologia de implantação de Produção mais Limpa aos processos produtivos permitirá a obtenção de soluções que contribuam mais para a solução

Tabela 2: Avaliação e listagem por ordem de prioridade das opções geradas.

\begin{tabular}{|c|c|c|c|}
\hline OPÇÕES P+L & BARREIRA & BENEFÍGIO & $\begin{array}{l}\text { ORDEM DE } \\
\text { PRIORIDADE }\end{array}$ \\
\hline Modificação do Produto & $\begin{array}{l}\text { Implica em mudança de } \\
\text { projeto o que às vezes não é } \\
\text { permitido. }\end{array}$ & $\begin{array}{l}\text { Redução de matéria-prima e } \\
\text { resíduo. }\end{array}$ & 3 \\
\hline Housekeeping & $\begin{array}{l}\text { Treinar e mudar a } \\
\text { mentalidade dos operadores } \\
\text { às novas práticas. }\end{array}$ & $\begin{array}{l}\text { - maior vida útil dos fluidos, } \\
\text { conseqüentemente menor } \\
\text { freqüência de descarte } \\
\text { - menor agressão à saúde do } \\
\text { operador }\end{array}$ & 1 \\
\hline $\begin{array}{l}\text { Mínima Quantidade de } \\
\text { Lubrificante (MQL) }\end{array}$ & $\begin{array}{l}\text { - mudança na máquina } \\
\text { - custo de implantação }\end{array}$ & $\begin{array}{l}\text { - redução do uso do fluido de corte } \\
\text { - eliminação dos resíduos/ }\end{array}$ & 2 \\
\hline Usinagem a Seco & $\begin{array}{l}\text { - alto investimento em } \\
\text { máquinas e ferramentas }\end{array}$ & $\begin{array}{l}\text { - elimina o custo com fluido de } \\
\text { corte } \\
\text { - elimina tempo de troca do fluido } \\
\text { - eliminação de resíduos }\end{array}$ & 4 \\
\hline
\end{tabular}


definitiva dos problemas ambientais, já que a prioridade da metodologia está baseada na identificação de opções de não geração dos resíduos produzidos nestes processos produtivos.

No caso dos processos de usinagem, podem-se avaliar várias oportunidades de aplicação de $\mathrm{P}+\mathrm{L}$, realizando algumas modificações no produto, mas especialmente no processo. Vários procedimentos podem ser adotados no Housekeeping, também pode ser realizada uma substituição de matérias-primas e tecnologias que permitam reduzir ou eliminar resíduos como, por exemplo, fluidos usados e cavacos. Além disso, é necessário agregar valores aos resíduos gerados, através de uma reciclagem fora do processo. O meio ambiente agradece.

\section{Artigo recebido em 03/10/2005 Aprovado para publicação em 27/02/2007}

\begin{abstract}
- Referências
ALVES, S. M. Adequação Ambiental do processo de retificação através de um novo conceito de fluido de corte. Tese (doutorado), 199 f., Departamento de Engenharia Mecânica, EESC/USP, São Carlos. 2005.
\end{abstract}

ALVES, S. M.; OLIVEIRA, J. F. G. Novos fluidos de corte adequados ao desempenho mecânico da retificadora e ao meio ambiente. Revista Máquinas e Metais. São Paulo, p. 28-43, janeiro, 2006.

ANDRÉS, L. F. A gestão ambiental em indústrias do Vale do Taquari: Vantagem com o uso das técnicas de Produção mais Limpa. Dissertação (mestrado), 86 f. Departamento de Administração, UFRGS, Porto Alegre, 2001.

BYRNE, G. Usinagem em ambiente limpo: não se trata apenas de higiene. Máquinas e Metais, São Paulo-SP, p. 6780, abril, 1996.
CNTL - Centro Nacional de Tecnologias Limpas. Disponível em www.rs.senai. br/cntl. Acesso em: 5 maio 2003.

DÖRR, J.; NOVASKI, O. Usinagem sem refrigeração. Máquinas e Metais, São Paulo, p. 18-27, mar. 1999.

DÖRR, J.; SAHM, A. A mínima quantidade de lubrificante avaliada pelos usuários. Máquinas e Metais, São Paulo, n. 418, p. 20-39, nov. 2000.

FILHO, F. T.; FERREIRA, J. R.; SANTOS, J. N.; DINIZ, A. E. O uso (ou não) da refrigeração/lubrificação no torneamento de aço endurecido. Máquina e Metais, São Paulo, p. 260-283, abril, 2001.

IGNÁCIO, E. A. Caracterização de Legislação Ambiental Brasileira voltada para a utilização de fluido de corte na indústria metal- mecânica. Dissertação (mestrado). Departamento de engenharia de produção, UFSC, Florianópolis, 1998.

LEMOS, A. D. C. A Produção mais Limpa como geradora de inovação e competitividade: o caso da fazendo cerro do tigre. Dissertação (mestrado). Departamento de Administração, UFRGS. Porto Alegre, 1998.

MACHADO, A. R.; DINIZ, A. E. Vantagens e desvantagens do uso (ou não) de fluidos de cortes. Máquinas e Metais, São Paulo, p. $134-151,2000$

MELLO, M. C. A. Produção mais Limpa: um estudo de caso na AGCO do Brasil. Dissertação (mestrado). Departamento de Administração,UFRGS. Porto Alegre, 2002.
QUEIROZ, J. L. L. Desenvolvimento de um protótipo de software para controle da variável ambiental na utilização do fluido de corte. Tese (doutorado). Departamento de Engenharia de Produção, UFSC, Florianópolis, 2001.

ROMM, Joseph J. Um passo além do qualidade: como aumentar seus lucros e produtividade através de uma administração ecológica. São Paulo: Futura, 1996.

SOKOVIC, M.; MIJANOVIC, K. Ecological aspects of cutting fluids and its influence on quantifiable parameters of the cutting process. Journal of Materials Processing Technology, n. 109, p. 181-189, 2001.

UNEP: United Nations Environmental Program. Disponível em http://www. unep.org/. Acesso em: 20 de set. 2004.

\section{- Sobre os autores}

\section{João Fernando Gomes de Oliveira}

Doutor em Eng. Mecânica pela EESC-USP

Professor Titular da Escola de Engenharia de São Carlos

End.: Av. Trabalhador São Carlense, 400 - Centro - 13566-590 - São Carlos - SP

Tel.: (16) 3373-9393 Fax: (16) 3373-9412

E-mail: jfgo@sc.usp.br

\section{Salete Martins Alves}

Doutora em Eng. Mecânica pela EESC-USP

Professora e pesquisadora da SOCIESC - Sociedade Educacional de Santa Catarina

End.: R. Albano Schmidt, 3333 - Boa Vista - 89206-001 - Joinville - SC

Tel.: (47) 3461-0160/ (47) 9985-5387 Fax: (47) 34610227

E-mail: salete.martins@sociesc.com.br 